\title{
The choice of informative parameters of the cardiovascular system for assessment of physiological effects of hypogravity
}

\author{
Anton Cherepov, ${ }^{1,}$, Daria Pozdeeva ${ }^{2}$, Elena Arkhipova ${ }^{2}$ \\ ${ }^{1}$ Lab of Neurobiology of Memory, P. K. Anokhin Institute of Normal Physiology, Moscow, Russia \\ ${ }^{2}$ Lab of Physicochemical and Ecological Pathophysiology, Institute of General Pathology and Pathophysiology, Moscow, Russia
}

\section{Email address:}

a.cherepov@nphys.ru (A. Cherepov)

\section{To cite this article:}

Anton Cherepov, Daria Pozdeeva, Elena Arkhipova. The Choice of Informative Parameters of the Cardiovascular System for Assessment of Physiological Effects of Hypogravity. American Journal of Life Sciences. Special Issue: Space Flight Factors: From Cell to Body.

Vol. 5, No. 1-2, 2014, pp. 48-57. doi: 10.11648/j.ajls.s.2015030102.18

\begin{abstract}
Changes in cardiovascular system (CVS) under conditions of hypogravity simulated using 7-and 21-day ortho- and antiorthostatic hypokinesia at different angles were studied. The aim of the experiment was selection of informative CVS parameters most sensitive to these conditions. Simultaneous recording of 26 CVS parameters on a spiroartheriocardiorythmograph showed that the most sensitive parameters were blood pressure (BP) variability indexes in functional tests: differences in groups with varying degrees of orthostatic hypokinesia $\left(+9.6^{\circ}\right.$ and $\left.+15^{\circ}\right)$ were observed starting from the first week of the experiment. By day 21, pronounced changes in the total spectral power of diastolic BP variability were noted in the group exposed to constant antiorthostasis. This parameter significantly surpassed the corresponding value in the groups with milder conditions. Significant increase in the LF component of diastolic BP in groups exposed to severe antiorthostasis and orthostasis was detected. Presumably, autonomic mechanisms affecting the systolic and diastolic BP under conditions of hypogravity simulation are different, at least partially.
\end{abstract}

Keywords: Systolic and Diastolic Blood Pressure, Simulated Hypogravity, Bed Rest, Heart rate Variability, Blood Pressure Variability

\section{Introduction}

Processes of adaptation to hypogravity and hypokinesia occur during space flights and under conditions of their terrestrial modeling. The most obvious effect of hypogravity on the human body is displacement of liquid media to the upper part of the body, which triggers the mechanisms providing long-term adaptation to the new conditions. These changes primarily affect the function of the cardiovascular system (CVS) and respiratory system (RS), which necessitates their continuous monitoring under conditions of hypogravity. For evaluation of the adaptation processes in CVS and RS, parameters of the autonomic balance and activity of the segmental and suprasegmental compartments of the autonomic nervous system that are responsible for adaptation to environmental changes, in particular, to weightlessness [1, $2,4]$.

The autonomic balance of CVS is usually assessed by heart rhythm variability (R-R intervals). However, heart rhythm oscillations are closely related to respiratory rate and both these systems determine variability of systolic and diastolic pressure (blood pressure variability; BPV) [5-9]. Hence, the data on HRV and BPV cannot be interpreted in the absence of synchronous respiration recording [3]. In our study, we used a spiroarteriocardiorhythmograph (SACR) allowing parallel recording of the respiratory and cardiovascular variability.

As a part of a complex study on theoretical and experimental validation of the model the physiological effects of hypogravity on austronauts during their stay on the lunar surface, hypogravity was simulated using ortho- and antiorthostatic hypokinesia ( $\mathrm{OH}$ and $\mathrm{ANOH})$.

In the part of the study described in this article, we focused on the analysis of a wide range of CVS and RS parameters under conditions of hypogravity simulation to identify the most important parameters characterizing the differences between the experimental groups. 


\section{Materials and Methods}

$\mathrm{OH}$ and $\mathrm{ANOH}$ experiments were performed on male volunteers in hospital settings. The experiments were performed in 7- and 21-day variants. The research procedures and methods were approved by the Commission on Biomedical Ethics at the Federal Research and Clinical Center of Specialized Medical Care and Medical Technologies, Federal Medico-Biological Agency of Russia; all volunteers signed Informed consent for participation in the study.

The 7-day experiment included 8 male volunteers (19-39 years) that were distributed into 2 groups ( 4 volunteers per group) and exposed to continuous 7-day head-up tilt bed rest (7-day $\mathrm{OH})$ at an angle of $+9.6^{\circ}$ (group $1 ;+9.6^{\circ} \mathrm{OH}$ ) or $+15^{\circ}$ (group $2 ;+15^{\circ} \mathrm{OH}$ ).

The 21-day experiment included 11 volunteers (19-39-year-old men) that also were distributed into 2 groups. The first group (5 volunteers) was subjected to 21-day tilt-down bed rest at an angle of $-6^{\circ}$ (ANOH group) (Fig. 2); these conditions simulated weightless space flight to the Moon with subsequent lunar orbiting. The second group (Selena; 6 volunteers) simulated space flight to the Moon with subsequent stay on the lunar surface. These volunteers were subjected to tilt-down bed rest (ANOH; $\left.-6^{\circ}\right)$ on days $1-5$ of the experiment followed by alternation of daytime orthostatic bed rest at an angle of $+9.6^{\circ}$ (from 7 am to $11 \mathrm{pm}$ ) and nighttime horizontal bed rest $\left(0^{\circ}\right.$; from $11 \mathrm{pm}$ to $\left.7 \mathrm{am}\right)$ on days $6-21$ of the experiment (Fig. 2).

\subsection{Spiroarteriocardiorhythmography: Principles and Instruments}

Individual functional sufficiency of the cardiorespiratory system was evaluated using a Spiroarteriocardiorhythmograph instrument complex (SACR, recommended by Ministry of Health Care and Social Development of the Russian Federation for clinical use; registration certificate \#29/03020703/5869-04, St. Petersburg) allowing simultaneous recording of the heart, vascular, and respiratory rhythms. The method makes it possible to calculate the relative contribution of sympathetic and parasympathetic autonomic nervous system (ANS) into heart rate (HR) and blood pressure (BP) regulation, integrated values of cardiogram intervals, parameters of lung ventilation, baroreflex parameters, etc.

Electrocardiogram (ECG) was recorded in standard lead I over 2 minutes. The time-amplitude parameters of PQRST complex and heart rhythm variability (HRV) were evaluated using statistic, geometric, and spectral parameters. HRV power in different frequency bands determined using Fourier-transform analysis characterizes ANS activity and the function of the central mechanisms of heart rate regulation. Three frequency bands can be distinguished in the spectra: very low frequency (VLF, $0-0.04 \mathrm{~Hz}$ ), low frequency (LF, $0.04-0.15 \mathrm{~Hz}$ ), and high frequency $(0.15-0.4 \mathrm{~Hz})$, which are measured in absolute values of power $\left(\mathrm{ms}^{2}\right)$. These values can also be presented in standardized units (LFn, HFn) calculated as the ratio of each spectral component to their sum. Index of autonomic balance $(\mathrm{AB}=\mathrm{LF} / \mathrm{HF})$ and index of centralization $(\mathrm{C}=(\mathrm{VLF}+\mathrm{LF}) / \mathrm{HF})$ were calculated from HRV spectral parameters.

Peripheral systolic and diastolic blood pressure (SBP and DBP, respectively) and their variability were measured on middle phalanx using the method of Penaz. From the parameters of BP pulse wave, hemodynamic parameters, stroke volume, and cardiac output were calculated using phase analysis of cardiac cycle and BP. Spontaneous arterial baroreflex sensitivity (BRS $=\mathrm{LF}_{\mathrm{M}} / \mathrm{LF}_{\mathrm{SBP}}$ ) was also evaluated. From geometric parameters of HRV (mode, mode amplitude, amplitude of oscillations, etc.), autonomic balance index, parameter of adequacy of regulation processes, autonomic rhythm index, and regulatory system strain index (SI) were calculated.

The only analogs of Spiroarteriocardiorhythmograph, Finapress Medical System [10] and its portable modification Portapress [11] manufactured by TNO company (the Netherlands) have no measuring spirometric channel, which makes impossible simultaneous analysis of respiration and circulation, but these options are successfully realized in the Spiroarteriocardiorhythmograph.

\section{7-day experiment}

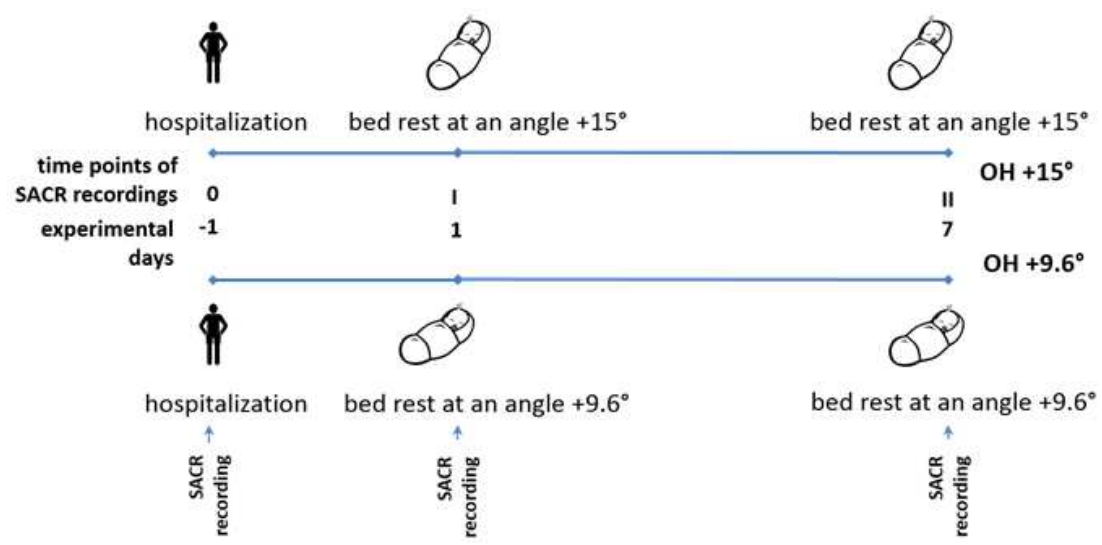

Figure 1. Design of the 7-day experiment. 

Effects of Hypogravity

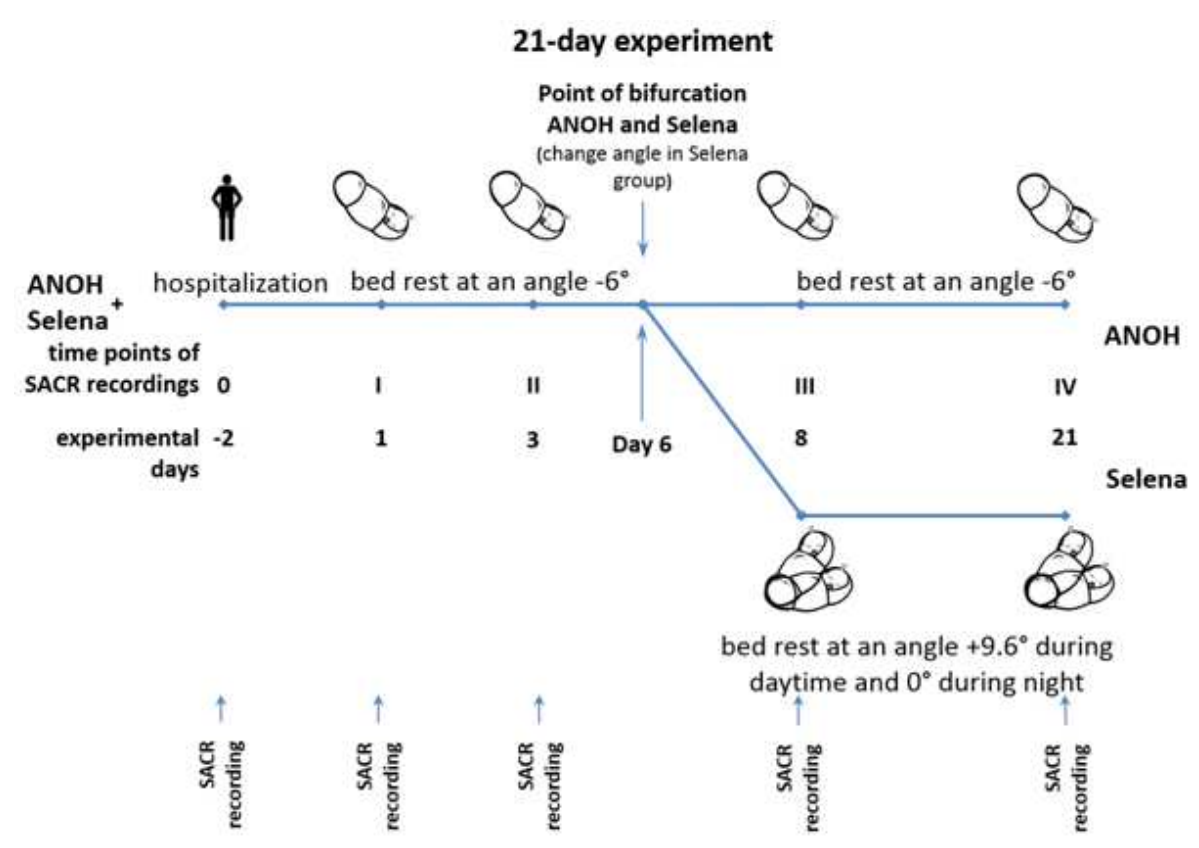

Figure 2. Design of the 21-day experiment.

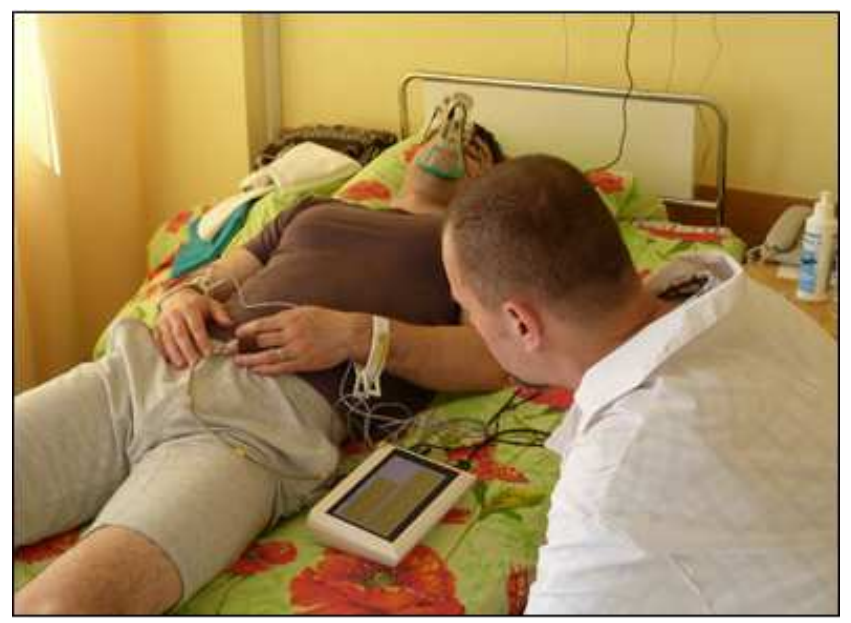

Figure 3. SACR recording.
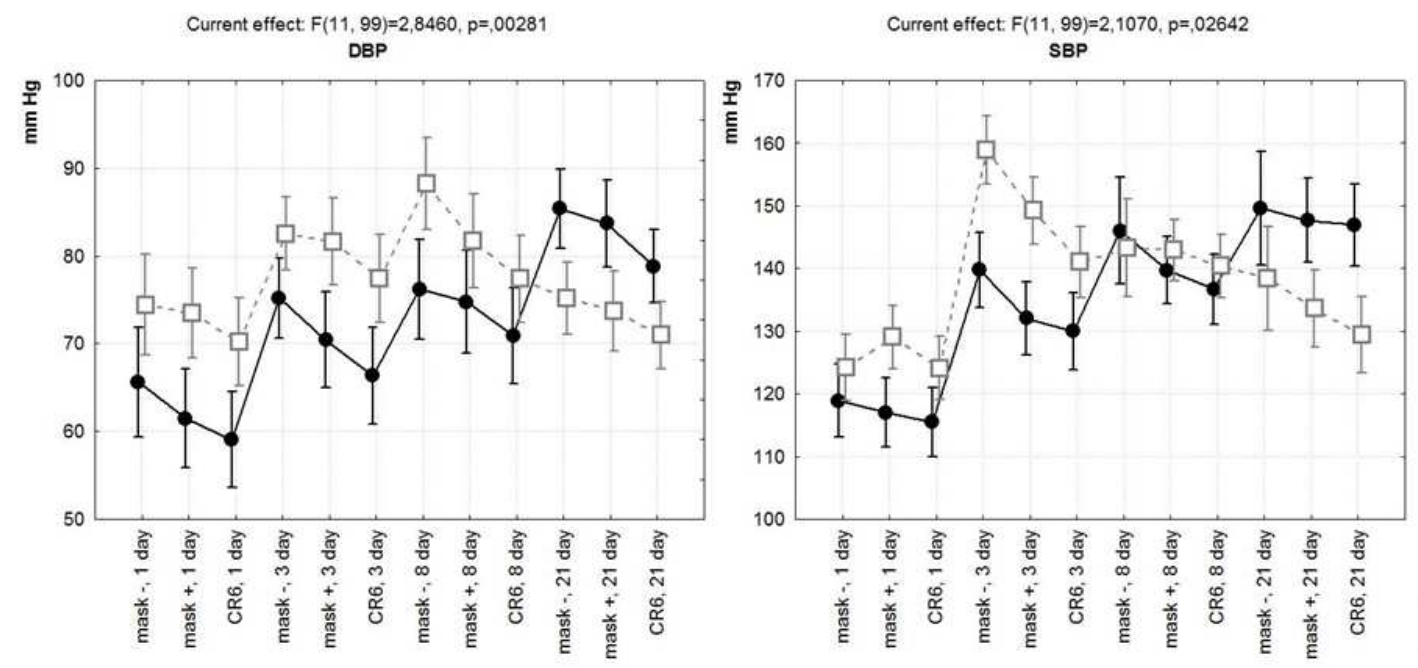

ANOH group

Figure 4. BP dynamics during hypogravity modeling (mean \pm SE). 

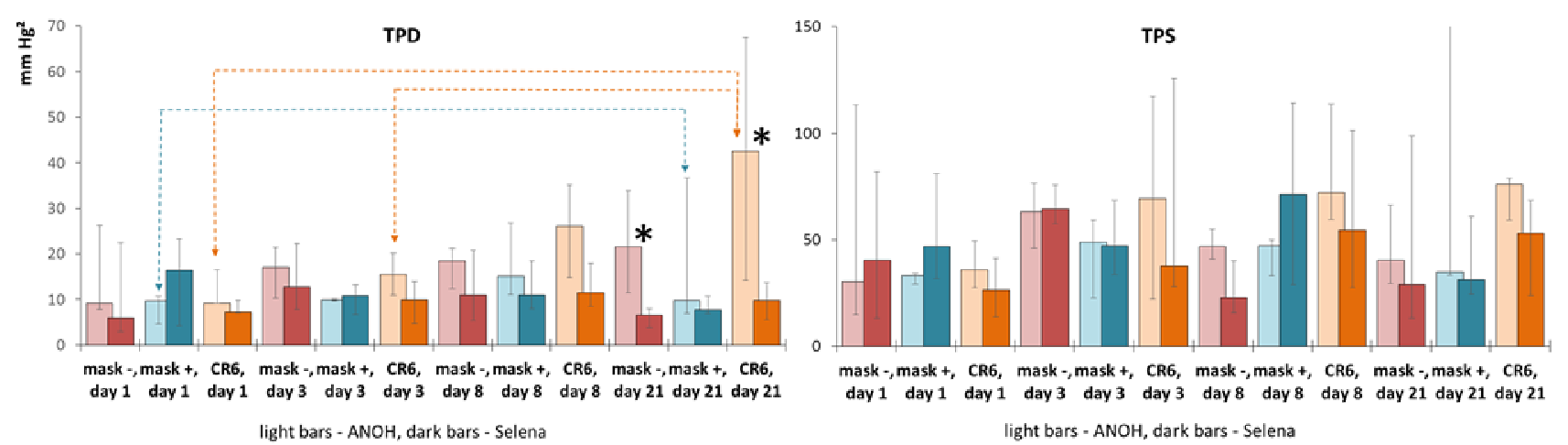

Figure 5. TPD and TPS during mask-off recording and two functional tests throughout the observation period. (the data are presented as median and $25 \%-75 \%)$. * - p<0,05, Mann-Whitney test; - - - p<0,05, Wilcoxon matched-pair test

\subsection{Conditions and Schedule of SACR Measurements}

\subsubsection{In 7-day experiment}

The first measurement was performed one day before $\mathrm{OH}$ simulation and then on days 1 and 7 of bed rest (time points 0 , I, and II, respectively) (Fig. 1). All measurements were performed in the morning (from 9 to $11 \mathrm{am}$ ).

\subsubsection{In 21-Day Experiment}

The measurements were performed 2 days before the start of ANOH modeling and then on days 3, 8, and 21 of bed rest (time points 0, I, II, III, IV, respectively) (Fig. 2). All measurements were performed at 9-11 am. It should be noted that Selena group volunteers on days $6-21$ of bed rest were examined in $2-4 \mathrm{~h}$ after transition from the horizontal $\left(0^{\circ}\right)$ to orthostatic $\left(+9.6^{\circ}\right)$ position.

The examination was carried out in the supine position (either horizontal or at the tilt prescribed by the experimental protocol; Fig. 3) and consisted of 3 continuous 2-min SACR recordings: 1) without respiratory masks and respiration recording (mask -); 2) with respiratory mask (functional test with increased "dead space", which according Trukhanov et al. [12], leads to redistribution of HR variability spectrum towards an increase in the high-frequency (HF) component) $($ mask +); 3) functional test or controlled respiration at a frequency of $0.1 \mathrm{~Hz}$ with the use of respiratory mask and respiration recording $\left(\mathrm{CR}_{6}\right)$. Breathing with a frequency of 6 times per minute induces significant BP shifts due to blood deposition in the lungs during inspiration followed by pronounced HR and BP baroreflex response [14].

Statistics. The data were expressed as means $\pm \mathrm{SE}$ or median with percentiles 25-75\%. Repeated measures ANOVA was used for evaluation of differences between the groups. For data not conforming normal distribution the nonparametric Mann-Whitney and Wilcoxon matched-pairs tests were used.

\section{Results}

The most striking and significant between-group differences were found for BP and its autonomic regulation in the 21-day experiment (between ANOH and Selena groups).

Figure 4 illustrates significant between-group differences in the dynamics of DBP and SBP (ANOVA for repeated measures). The significance of differences were $\mathrm{p}=0.003$ for DBP and $\mathrm{p}=0.03$ for SBP.

To answer the question in which period of our experiment these differences were significant, we should exclude between-group differences preceding the tilt changes in both groups (day 6). CVS and RS parameters were recorded in the following time points: 0 - 2 days before bed rest, I - day 1 of the experiment, II - day 3 of the experiment, III - day 8 of the experiment, IV - day 21 of the experiment (see experimental protocol). To exclude between-group differences preceding the tilt changes, we divided the study period into 2 intervals: A - from point I to point II (inclusively), when the tilt was the same in ANOH and Selena groups $\left(-6^{\circ}\right)$; B - from point III to point IV, when the tilts were different in these groups.

The results presented in Table 1 show that significant differences in the dynamics of DBP appeared during interval $\mathrm{B}$ and were absent during interval $\mathrm{A}$, when the examinees were under the same conditions.

In ANOH and Selena groups, SBP changed more rapidly than DBP in response to transition from antiorthostatic to orthostatic position between days 3 and 8 of bed rest, which can be seen from the analysis of between-group differences in SBP on days 3-21. ANOVA revealed significant differences between the ANOH and Selena groups during this period: $\mathrm{F}(8$, $72)=2.4117, \mathrm{p}=0.0229 *$.

Based on this result, we analyzed changes in autonomic regulation of BP by assessing DBP and SBP variability using spectral analysis of BP rhythms. Figure 5 shows the dynamics of the total power of DBP and SBP spectra over the entire observation period.

The total power of DBP variability spectrum (TPD) significantly increased on day 21 of bed rest in the ANOH group exposed to invariable and more rigid conditions than Selena group. This increase in TPD was observed on day 21 during both mask-on and mask-off recording and especially during controlled respiration. No significant differences in the total power of SBP spectra (TPS) were found.

Further, we present the results of the analysis of intra- and intergroup differences in the frequency components of $\mathrm{BP}$ variability (HFD/S, LFD/S, VLFD/S) during morning measurements. 
Analysis of the HF component of SBP and DBP variability (HFS/D) revealed significant intra- and intergroup differences in HFS (Fig. 6). In the ANOH group, the HF component of SBP variability (HFS) significantly increased by day 8 in comparison with the results of examination 2 days before the experiment (time point 0) and in comparison with the corresponding value in Selena group. These differences were more pronounced during mask-off recording (mask-) (Fig. 6). Similar changes were detected for HFD, but they were statistically insignificant.

Table 1. Between-group differences (ANOVA for repeated measures) in absolute BP values before and after ANOH tilt change (multivariate analysis)

\begin{tabular}{llll}
\hline \multirow{2}{*}{ Compared groups } & Time interval & & \\
\cline { 2 - 4 } & Total observation period (days 1-21) & Interval A (days 1-3) & Interval B (days 8-21) \\
\hline $\mathrm{DBP}_{\mathrm{ANOH}}$ vs DBP & $\mathrm{F}(11,99)=2,8460, \mathrm{p}=0,00281^{*}$ & $\mathrm{~F}(5,45)=0,12573, \mathrm{p}=0,98568$ & $\mathrm{~F}(5,45)=4,8511, \mathrm{p}=0,000124 *$ \\
$\mathrm{SBP}_{\mathrm{ANOH}}$ vs SBP & $\mathrm{F}(11,99)=2,1070, \mathrm{p}=0,02642^{*}$ & $\mathrm{~F}(5,45)=0,45271, \mathrm{p}=0,80908$ & $\mathrm{~F}(5,45)=1,2787, \mathrm{p}=0,28977$ \\
\hline
\end{tabular}

* $-\mathrm{p}<0,05$
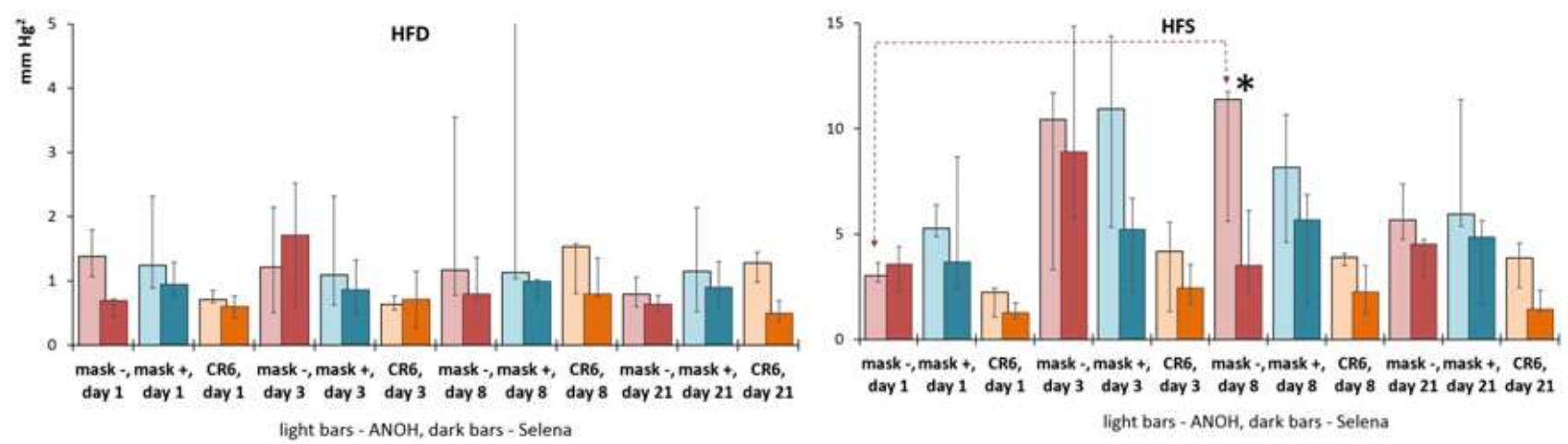

Figure 6. HFD and HFS during mask-off recording and two functional tests throughout the observation period. (the data are presented as median and $25 \%-75 \%)$. * - $p<0,05$, Mann-Whitney test; - - - p<0,05, Wilcoxon matched-pair test.

Table 2. Between-group differences (ANOVA for repeated measures) in standardized BP values before and after ANOH tilt change (multivariate analysis)

\begin{tabular}{llll}
\hline \multirow{2}{*}{ Compared groups } & Time interval & \\
\cline { 2 - 4 } & Total observation period $($ days 1-21) & Interval A (days 1-3) & \multicolumn{1}{c}{ Interval B (days 8-21) } \\
\hline stDBP $_{\mathrm{ANOH}}$ vs stDBP & $\mathrm{F}(11,99)=3,0975, \mathrm{p}=0,00129 *$ & $\mathrm{~F}(5,45)=0,57644, \mathrm{p}=0,71769$ \\
$\mathrm{stSBP}_{\mathrm{ANOH}}$ vs stSBP & $\mathrm{F}(11,99)=1,9191, \mathrm{p}=0,04558^{*}$ & $\mathrm{~F}(5,45)=2,1676, \mathrm{p}=0,07454$ & $\mathrm{~F}(5,45)=1,4183, \mathrm{p}=0,23601$ \\
\hline
\end{tabular}

$*-\mathrm{p}<0,05$

Analysis of the LF component of SBP and DBP variability (LFS/D) revealed significant intra- $(\mathrm{ANOH}-\mathrm{ANOH})$ and intergroup (ANOH-Selena) differences only for LFD.

In the ANOH group, the LF component of DBP variability (LFD) significantly increased by experimental day 21 in comparison with both day 1 (time point I) and corresponding value in the Selena group. This increase was most pronounced during functional test with controlled respiration.

In the range of very low frequencies (VLFD/S) (Fig. 8), a significant increase was observed for VLF component of DBP (VLFD) by day 21 of the experiment in the ANOH group in comparison with day 1 in the same group and in comparison with Selena group; these differences reached the level of statistical significance in the mask-off measurement (Fig. 8).

Comparison of the results the 7-day experiment in $+9.6^{\circ} \mathrm{OH}$ and $+15^{\circ} \mathrm{OH}$ groups revealed significant intergroup differences in the parameters of autonomic regulation of both SBP (Fig. 9) and DPB (Fig. 10).

Figures 9 and 10 illustrate the increase in total power of SBP and DBP spectra (TPS and TPD, respectively) for the $+9.6^{\circ} \mathrm{OH}$ group in comparison with the $+15^{\circ} \mathrm{OH}$ group, especially in the mask-on functional test. Since in these experiments significant differences in BP variability were found only during functional tests (mask-on and controlled respiration), we further discuss only these parameters (Fig. 9 and 10).

The greatest contribution into TPS increase in the $+9.6^{\circ} \mathrm{OH}$ group was made by the HF component (HFS) and in the mask-on test - by the VLF component (VLFS) (Fig. 9). The greatest contribution into TPD increase in the $+9.6^{\circ} \mathrm{OH}$ group was made by HF and LF components (HFD and LFD) (Fig. 10). These findings attest to the involvement of different levels of SBP and DBP regulation into this autonomic shift.

In order to avoid distortion of changes due to individual variability in the 7-day experiment, we used standardized values (Figures 9 and 10 show deviations of the parameters from the values obtained on day 1 of the experiment).

It should be noted that in the 21-day experiment, the changes in standardized BP (stBP) and absolute BP were similar (Table 1 and 2). stDBP and stSBP were calculated as the ratio of absolute parameters to DBP and SBP values on day 1 of the experiment (time point I; see Fig. 2). Significant between-group differences for stDBP were observed during the period from day 8 to day 21 (interval B).

ANOVA revealed significant differences in stSBP between the $\mathrm{ANOH}$ and Selena groups during the period from 3 to day 
21 (time points II-IV; see experimental protocol): $\mathrm{F}(8$, 72) $=2.5211, \mathrm{p}=0.01779 *$.
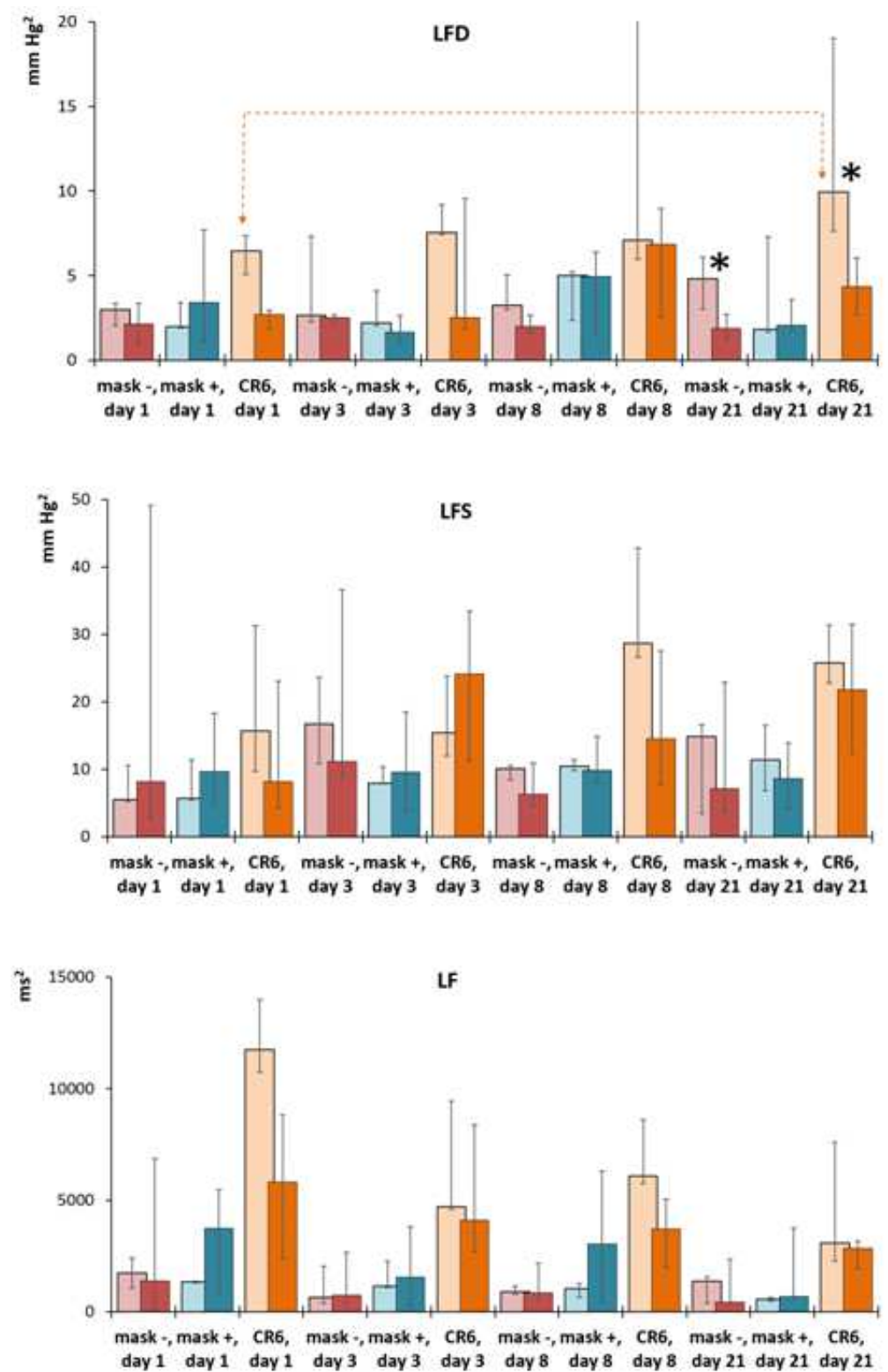

light bars - ANOH, dark bars - Selena

Figure 7. LFD, LFS, and LF during mask-off recording and two functional tests throughout the observation period. (the data are presented as median and $25 \%-75 \%)$. * $p<0,05$, Mann-Whitney test $;-\ldots p<0,05$, Wilcoxon matched-pair test.

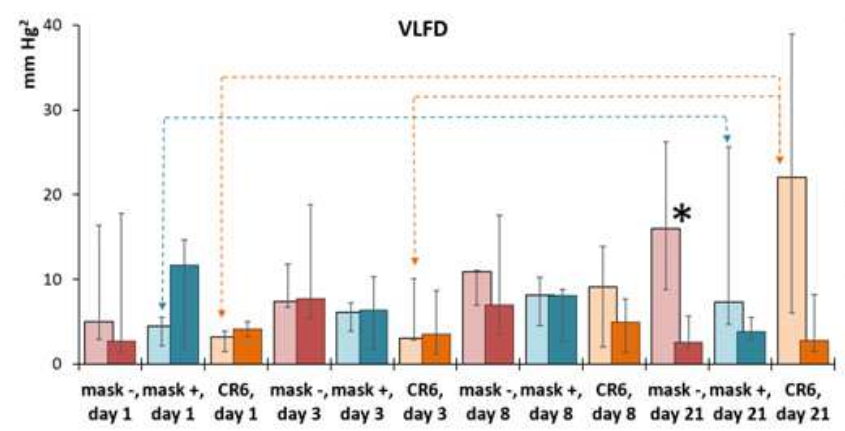

light bars - ANOH, dark bars - Selena

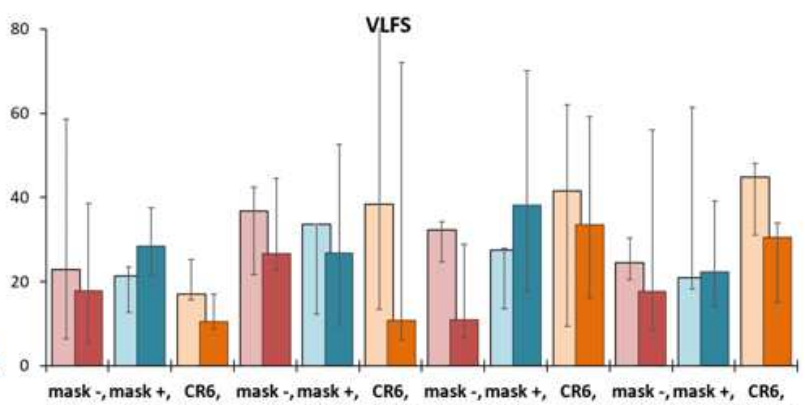

day 1 day 1 day 1 day 3 day 3 day 3 day 8 day 8 day 8 day 21 day 21 day 21 light bars - ANOH, dark bars - Selena

Figure 8. VLFD and VLFS during mask-off recording and two functional tests throughout the observation period. (the data are presented as median and $25 \%-75 \%)$. * - p<0,05, Mann-Whitney test; - - - p<0,05, Wilcoxon matched-pair test. 

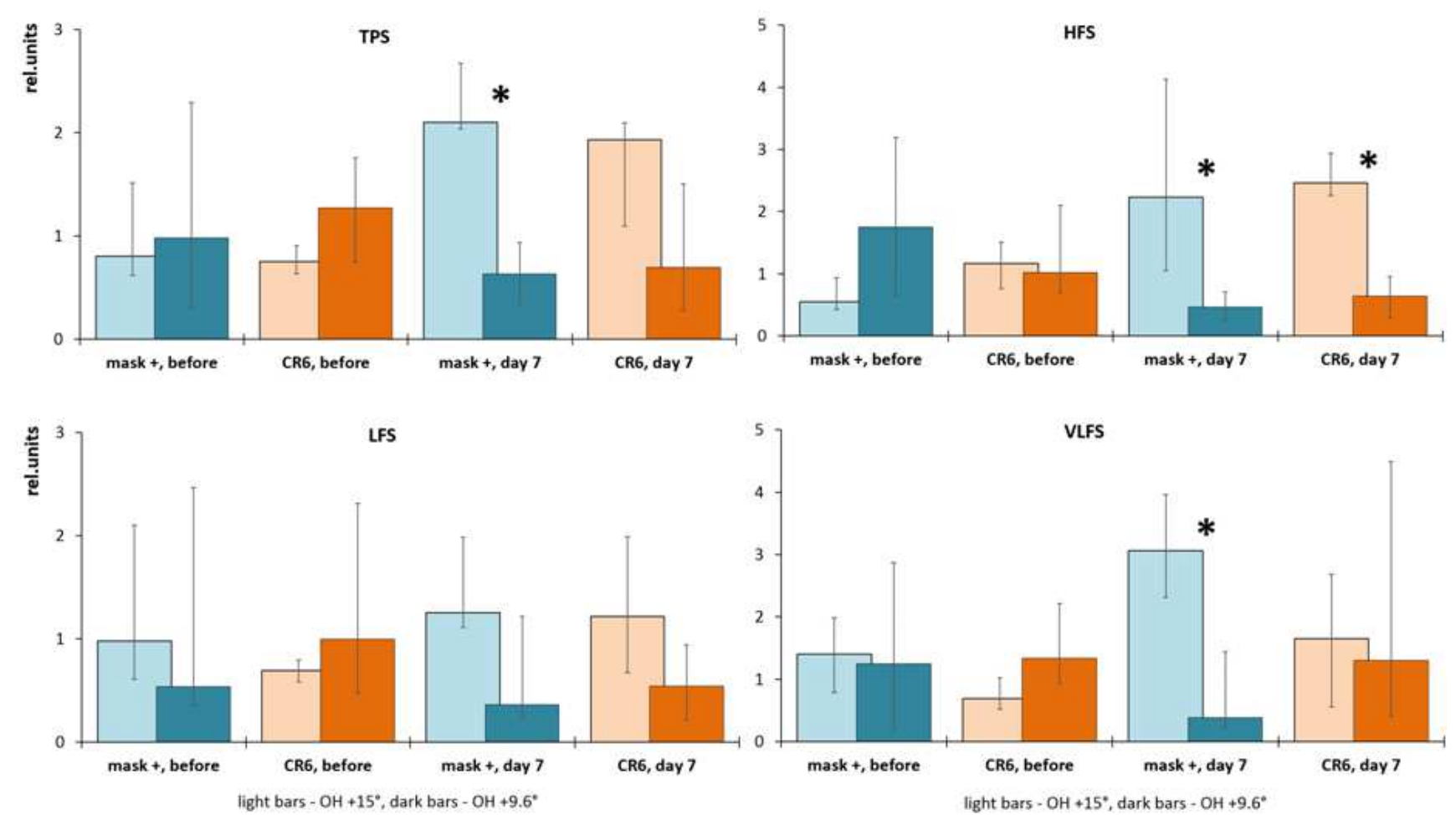

Figure 9. TPS and its components HFS, LFS, and VLFS before and day 7 hypogravity simulation in mask-on and controlled respiration tests (the data are presented as median and 25\%-75\%). * $-p<0,05$, Mann-Whitney test.
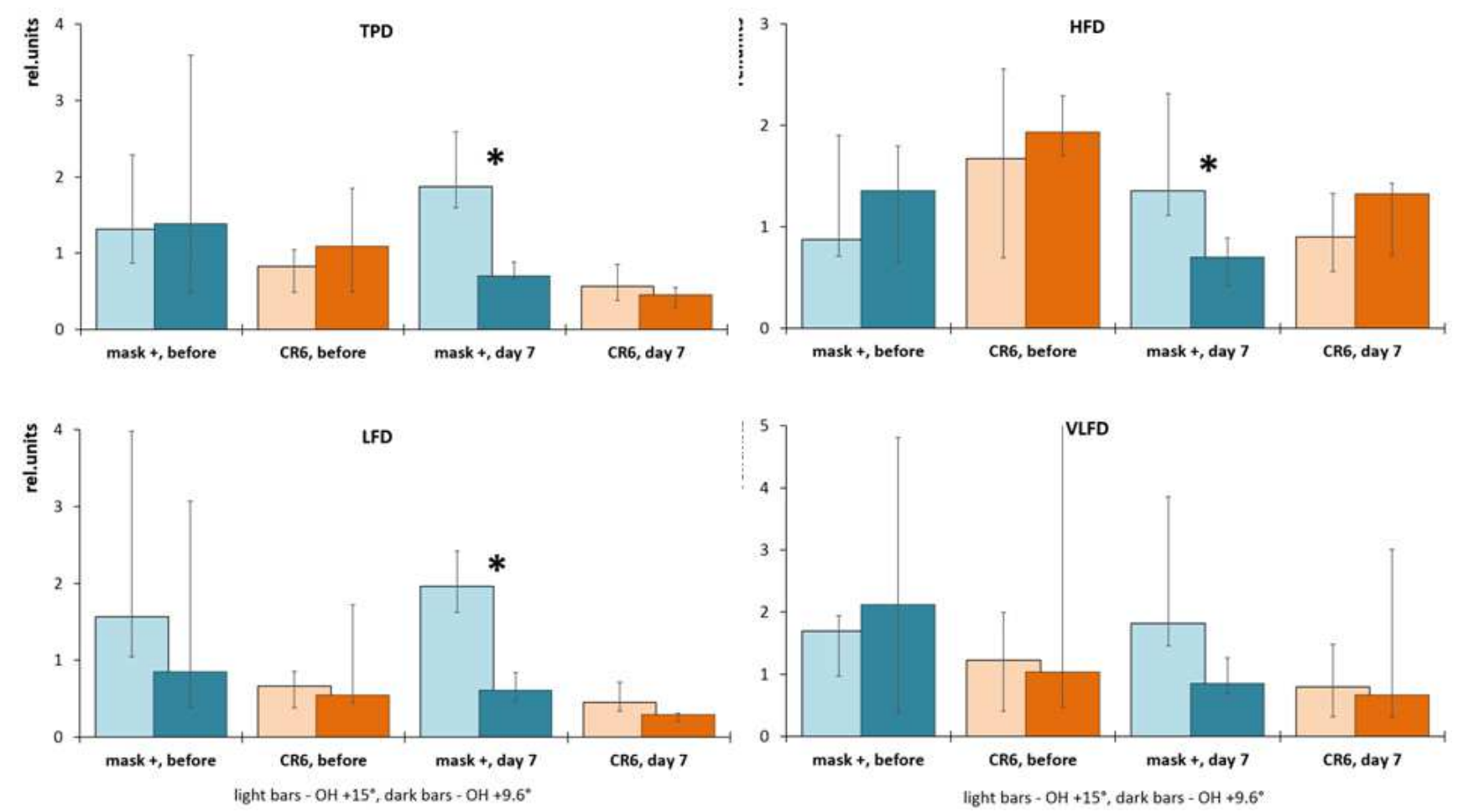

Figure 10. TPD and its components HFD, LFD, and VLFD before and day 7 hypogravity simulation in mask-on and controlled respiration tests (the data are presented as median and $25 \%-75 \%)$. * $p<0,05$, Mann-Whitney test.

\section{Discussion}

The most pronounced SBP spectral power variability and drastic changes in this parameter in response to orthostatic exposure were observed by A. P. Isaev et al. in their survey of young athletes [13]. Moreover, the total power of oscillations consistently increased only during recording of pulse wave amplitude in small vessels of the toe under conditions of both active and passive orthostasis in contrast to opposite oscillation spectra in large vessels (tibial vessels and aorta) in 
response to active or passive orthostasis. This agrees with our findings on BP variability in response to modulation of chronic orthostasis conditions (tilt change or transition from antiorthostasis to orthostasis) under similar conditions of BP recording on finger vessels in the supine position.

Rhythmic changes in SBP and, hence, in TPS are primarily related to variability of the pumping function of the heart [14] and TP of HR as the main indicator of this variability; this explains the absence of pronounced concordant changes in TPS (Fig. 5) in the examinees and agrees with the absence of significant intra- and intergroup differences in TP of their HR throughout the 21-day experiment. This can be explained by individual variability of changes in HR under conditions of ANOH and $\mathrm{OH}$ in the examinees, in particular, TP and other parameters of HR variability [15].

High-frequency BP modulations have more pronounced effect on the systolic component of BP variability (HFS) than on its diastolic component. It is known that this frequency range is mainly determined by respiration rate and via the vagus nerve modulates $H R$ and shifts the variability spectrum towards HF range, which, in turn, affects SBP variability in the same frequency range (HFS) [16]. HFS attained significant intra- and intergroup differences only on day 8 of the 21-day experiment; however, no significant changes in the $\mathrm{HF}$ component of HR variability were revealed due to great individual variability. A similar picture was observed in the 7-day experiment.

Significant increase in the integral index of DBP (but not $\mathrm{SBP}$ ) variability (TPD) under conditions of long-term ANOH agrees with the fact that this parameter is closely related to the tone, rigidity, and myogenic activity of smooth muscle cells in the peripheral vessels $[15,17]$, and its significant changes logically reflect the consequences of long-term antiorthostatic and orthostatic hypokinesia (redistribution of body fluids, changes salt-water balance, etc.) [18, 19].

The LF component of DBP variability (LFD) demonstrated most pronounced changes under conditions of orthostasis, especially in the respiration tests (mask-on recording or controlled respiration at a frequency of $0.1 \mathrm{~Hz}$ ). The blood flow or pressure oscillation component in this frequency range was sensitive to various factors [20, 21]. Physiological mechanisms of slow $(\sim 0.1 \mathrm{~Hz}) \mathrm{HR}$ and BP oscillations are elusive, but it is quite clear that slow HR oscillations are secondary, reflectory, and cannot be determined by a single cause [22]. Moreover, according to Cevese et al., BP fluctuations are determined by changes in the vascular resistance, but not changes in HR and cardiac contractility [23]. Variability of the skin microvasculature blood filling in humans also demonstrates oscillations at a frequency of 0.1 $\mathrm{Hz}$ [24] and, according to some authors, these fluctuations at the capillary level have myogenic origin $[25,26]$. Cooley et al. have demonstrated that slow $\mathrm{HR}$ and $\mathrm{BP}$ oscillations have different nature [27]. This agrees with the results of our experiments: no significant differences between ANOH and Selena groups and between $+9.6^{\circ} \mathrm{OH}$ and $+15^{\circ} \mathrm{OH}$ groups were observed in the spectral power of HR variability in contrast to $\mathrm{BP}$ variability (in particular, DBP). The most pronounced intergroup differences were observed in the LFD component (Fig. 7), when the rhythm with a frequency of 0.1 $\mathrm{Hz}$ corresponding to $\mathrm{LF}$ range was set by controlled respiration. These differences are most likely associated with long-term blood redistribution in the body and changes in peripheral (capillary) blood supply [19], but not with rhythmic changes in HR. Other stimuli, e.g. stimuli from afferent veins, interoceptors responding to organ displacement in the abdominal cavity, and vestibular apparatus closely related to the sympathetic nervous system seem to contribute to potentiation of slow waves, such as $\operatorname{BP}$ and $\operatorname{HR}[28,29,30]$ (which was seen from enhancement of LF component of HR variability spectra; Fig. 7), but do not reflect the differences in the status of examinees exposed to different of chronic orthostasis modes.

Intergroup changes in $\mathrm{BP}$ variability in the VLF range (VLFS/D) in our experiments are contradictory, as well as the assumption on the nature of waves in HR and BP variability in this range [19]. These changes could hardly be attributed to the direct effects of chronic anti- and orthostasis. However, bearing in mind the hypothesis proposed by Baevsky et al. on suprasegmental (hypothalamic and higher levels) nature of these oscillations [31-33], we can assume that they are related to psycho-emotional stress affecting the cardiovascular system, but this assumption requires additional analysis.

It can be concluded that the most sensitive parameters were BP variability indexes in functional tests that differed in groups with varying degrees of orthostatic hypokinesia $\left(+9.6^{\circ}\right.$ $\mathrm{OH}$ and $\left.+15^{\circ} \mathrm{OH}\right)$ starting from the first week of the experiment. This confirms high information value of these parameters in studies of orthostatic and antiorthostatic hypokinesia. By day 21 of the experiment, pronounced changes in TPD were noted in the group exposed to constant antiorthostasis (ANOH). This parameter significantly surpassed the corresponding value in the Selena group with milder $\mathrm{OH}$ conditions. Autonomic mechanisms affecting the SBP and DBP under conditions of hypogravity simulation are different, at least partially. This is seen from significant increase in the LF component of DBP in groups exposed to severe antiorthostasis and orthostasis (ANOH and $+15^{\circ} \mathrm{OH}$ groups). Autonomic regulation of SBP varied earlier (by 7-8 days) and primarily affected HFS, while this imbalance was leveled by day 21 (in contrast to LFS).

\section{References}

[1] R.M. Baevsky, "Noninvasive methods in space cardiology," J.Cardiovasc Diagn Proced, No. 14, 1997, pp. 161-171.

[2] R.M. Baevsky, V.M. Baranov, I.I. Funtova, A. Diedrich, A.V. Pashenko, A.G. Chernikova, J. Drescher, J. Jordan, J. Tank. "Autonomic cardiovascular and respiratory control during prolonged spaceflights aboard the International Space Station," J.Appl Physiol., vol. 103, 2007, No. 1, pp. 156-161.

[3] R.M. Baevsky, I.I. Funtova, A. Diedrich, A.V. Pashchenko, A.G Chernikova, J. Drescher, V.M. Baranov, J. Tank, "Autonomic function testing on board the ISS - update on "Pneumocard"”, Acta Astronáutica, vol. 61, No. 7-8, 2007, pp. 672-675. 
[4] W.H. Cooke, J.E. IV Ames, A.A. Crossman, J.F. Cox, T.A. Kuusela, K.U. Tahvanainen, L.B. Moon, J. Drescher, F.J. Baisch, T. Mano, B.D. Levine, C.G. Blomqvist, D.L. Eckberg, "Nine months in space: effects on human autonomic cardiovascular regulation," J. Appl Physiol., vol. 89, 2000, pp. $1039-1045$.

[5] J.M. Fritsch-Yelle, J.B. Charles, M.M. Jones, M.L. Wood, "Microgravity decreases heart rate and arterial pressure in humans," J. Appl Physiol.,vol. 80, 1996, pp. 910-914.

[6] P.F. Migeotte, G.K. Prisk, M. Paiva. "Microgravity alters respiratory sinus arrhythmia and short-term heart rate variability in humans," Am. J. Physiol. Heart Circ. Physiol. vol. 284, 2003, pp. H1995-H2006.

[7] M.V. Pitzalis, F. Mastropasqua, F. Massari, A. Passantino, R. Colombo, A. Mannarini, C. Forleo, P. Rizzon. "Effect of respiratory rate on the relationships between RR interval and systolic blood pressure fluctuations: a frequency-dependent phenomenon," Cardiovascular Research., vol. 38, 1998, No. 2, pp. 332-339.

[8] C. Julien, S.C. Malpas, H.M. Stauss, "Sympathetic modulation of blood pressure variability," J. Hypertens. vol. 19. 2001. pp. 1707-1712.

[9] J.A. Taylor, D.L. Eckberg, "Fundamental relations between short-term RR interval and arterial pressure oscillations in humans," Circulation. vol. 93. 1996. pp. 1527-1532.

[10] B. Silke, D. McAuley, "Accuracy and precision of blood pressure determination with the Finapres: an overview using re-sampling statistics," J. Hum Hypertens, vol. 12, No. 6, 1998, pp. 403-409.

[11] T.F. Schmidt, J. Wittenhaus, T.F. Steinmetz, P. Piccolo, H. Lüpsen, "Twenty-four-hour ambulatory noninvasive continuous finger blood pressure measurement with PORTAPRES: a new tool in cardiovascular research," J. Cardiovasc. Pharmacol., vol. 19, 1992, Suppl 6, pp. 117-145.

[12] A.I. Trukhanov, N.B. Pankova, N.N. Khlebnikova \& M.Yu. Karganov, "The Use of Spiroarteriocardiorhythmography as a Functional Test for Estimating the State of the Cardiorespiratory System in Adults and Children," Human Physiology. vol. 33, No. 5, 2007, pp. 585-594.

[13] A.P. Isaev, S.A. Kabanov, A.R. Sabirjanov, "Features of autonomic regulation of wave processes in the central and peripheral of hemodynamic in young athletes (on an example of sambo-wrestling)," Theory and practice of physical training, No. 1, 2002, pp. 40-43. (in Russian).

[14] A.P. Romanchuk, "The Complex Approach to a Multipurpose Estimation of a Sportsmen Condition," In:"Polysystemic Approach to School, Sport and Environment Medicine”, M. Karganov ed., - OMICS Group eBooks, 2013, - ISBN: 978-1-63278-000-3, pp. 54-86, - DOI: 10.4172, http://esciencecentral.org/ebooks/polysystemic-approach/com plex-approach.php

[15] R.M. Baevsky, I.I. Funtova,A.G. Chernikova, "Problems of heart rhythm variability evaluation in Space Medicine." Heart rate variability: Theoretical background and practical application. Abstracts of the fourth symposium with international participation. November 19-21, 2008, pp. 24-27, Izhevsk, Russia, (in Russian).

[16] A.R. Kiselev, V.I. Gridnev, "Oscillatory processes in autonomic regulation of the cardiovascular system (Review)," Saratov
Journal of Medical Scientific Research. vol. 7, 2011, No. 21.pp. 34-39 (in Russian).

[17] S. Bertuglia, A. Colantuoni, M. Intaglietta, "Effects of L-NMMA and indomethacin on arteriolar vasomotion in skeletal muscle microcirculation of conscious and anesthetized hamsters," Microvasc. Res. vol. 48, 1994, pp. 68-84.

[18] R.M. Baevsky, V.M. Baranov, J. Tank, E. S. Luchitskaya, I.I. Funtova, A.G. Chernikova, "Analysis of heart rhythm variability and assessment of the state of the myocardium during space flights in tests with fixed respiration rate and breath holding." Heart rate variability: Theoretical background and practical application. Abstracts of the fourth symposium with international participation. November 19-21, 2008, pp. 27-30, Izhevsk, Russia (in Russian).

[19] V. M. Khayutin, E. V. Lukoshkova, "Heart rate oscillations: spectral analysis." Vestnik Aritmologii. vol. 26, 2002, No. 9, pp. 10-21 (in Russian).

[20] Y. Yan, G. Shen, K. Xie, C. Tang, X. Wu, Q. Xu, J. Liu, J. Song, X. Jiang, E. Luo, "Wavelet analysis of acute effects of static magnetics field on resting skin bloodflow at the nail wall in young men,” Microvasc. Res., vol. 82, 2011, pp. 277-283.

[21] L. Bernardi, C. Porta, G. Casucci, R. Balsamo, N.F. Bernardi, R Fogari, P. Sleight, "Dynamic interactions between musical, cardiovascular, and cerebral rhythms in humans," Circulation, vol. 119, 2009, pp. 3171-3180.

[22] Bernardi L., Passino C., Spadacini G., F. Valle, S. Leuzzi, M. Piepoli, P. Sleight, "Arterial baroreceptors as determinants of $0.1 \mathrm{~Hz}$ and respiration-related changes in blood pressure and heart rate spectra," In: "Frontiers of blood pressure and heart rate analysis." M. Di Rienzo, G. Mancia, G. Parati, A. Pedotti, A. Zanchetti ed., Amsterdam. IOS Press. 1997. pp. 241-252, ISBN: 978-90-5199-312-7(print)/ 978-1-60750-879-3(online), DOI: $10.3233 / 978-1-60750-879-3-241$

[23] A. Cevese, R. Grasso, R. Poltronieri, F. Schena, "Vascular resistance and arterial pressure low-frequency oscillation in the anesthetized dog," Am. J. Physiol. vol. 268, 1995, No. 1, pp. H7-H16.

[24] "Internal synchronization of the main $0.1-\mathrm{Hz}$ rhythms in the autonomic control of the cardiovascular system," A.R. Kiselev, A.B. Bespiatov, O.M. Posnenkova, et al. Fiziologiya Chekoveka, vol. 33, 2007, No. 2, pp. 69-75 (in Russian).

[25] A. I. Krupatkin. "Blood flow oscillations at a frequency of about $0.1 \mathrm{~Hz}$ in skin microvessels do not reflect the parasympathetic regulation of their tone," Fiziologiya Chekoveka, vol. 35, 2007, No. 2, pp. 60-69 (in Russian).

[26] A.A. Grinevich, A.V. Tankanag, N.K. Chemeris, "Role of elasticity of blood vessels in formation of highly amplitude oscillations of a blood flow with frequency of $0.1 \mathrm{~Hz}$," Mathematical Biology and Bioinformatics, vol. 9, 2014. No. 2, pp. 341-358.

[27] R.L. Cooley, N. Montano, C. Cogliati, P. van de Borne, W. Richenbacher, R. Oren, Somers VK.. "Evidence for a central origin of low-frequency oscillation in RR-interval variability," Circulation. vol. 98, No. 6, 1998, pp. 556-561.

[28] M. Michaelis, R. Göder, H.J. Häbler, and W. Jänig. "Properties of afferent nerve fibers supplying the saphenous vein in the cat," J. Physiol., vol. 474, 1994, No. 2, pp. 233-243. 
[29] V.M. Khayutin, R.S. Sonina, E.V. Lukoshkova, Central organization of vasomotor control." Moscow, Meditsina, 1977, p. 352 (in Russian).

[30] Yates BT. "Vestibular influences on the autonomic nervous system.” Ann NY Acad Sci 1996; vol. 781: pp. 458-473.

[31] R.M. Baevsky, O. I. Kirillov, S. Z. Kletskin. "Mathematical analysis of changes in heart rate during stress." Moscow, 1984 (in Russian).
[32] A.V. Elfimov. "Influence of subsegental compartments of the autonomic nervous system on heart rate," A.V. Elfimov, I.V. Filippov. Mechanisms of Visceral System Functioning. St.Petersburg. I.P.Pavlov Institute of Physiology, Russian Academy of Sciences, 2001, pp. 118-119 (in Russian).

[33] N. B. Khaspekova, "Regulation of heart rhythm variability in healthy individuals and patients with psychogenic and organic pathologies of the brain." Doctor of Medical Science Dissertation. Moscow, 1996, p. 217 (in Russian). 